\title{
Saline versus $5 \%$ dextrose in water as a drug diluent for critically ill patients: a retrospective cohort study
}

\author{
Yukari Aoyagi*, Takuo Yoshida, Shigehiko Uchino, Masanori Takinami and Shoichi Uezono
}

\begin{abstract}
Background: The choice of intravenous infusion products for critically ill patients has been studied extensively because it can affect prognosis. However, there has been little research on drug diluents in this context. The purpose of this study is to evaluate the impact of diluent choice (saline or 5\% dextrose in water [D5W]) on electrolyte abnormalities, blood glucose control, incidence of acute kidney injury (AKI), and mortality.

Methods: This before-after, two-group comparative, retrospective study enrolled adult patients who stayed for more than $48 \mathrm{~h}$ in a general intensive care unit from July 2015 to December 2018. We changed the default diluent for intermittent drug sets in our electronic ordering system from D5W to saline at the end of 2016.

Results: We included 844 patients: 365 in the D5W period and 479 in the saline period. Drug diluents accounted for $21.4 \%$ of the total infusion volume. The incidences of hypernatremia and hyperchloremia were significantly greater in the saline group compared to the D5W group (hypernatremia 27.3\% vs. 14.6\%, $p<0.001$; hyperchloremia $36.9 \%$ vs. $20.4 \%, p<0.001$ ). Multivariate analyses confirmed the similar effects (hypernatremia adjusted odds ratio (OR), 2.43; 95\% confidence interval (Cl), 1.54-3.82; hyperchloremia adjusted OR, 2.09; 95\% Cl, 1.31-3.34). There was no significant difference in the incidences of hyperglycemia, AKI, and mortality between the two groups.
\end{abstract}

Conclusions: Changing the diluent default from D5W to saline had no effect on blood glucose control and increased the incidences of hypernatremia and hyperchloremia.

Keywords: Critical care, Diluent, Saline, Dextrose in water, Hyperglycemia, Hypernatremia

\section{Introduction}

Management of serum electrolyte and glucose levels among critically ill patients is essential because these abnormalities have been reported to be associated with acute kidney injury (AKI) and mortality [1-4]. Thus, clinicians pay attention to the choice of intravenous infusion products which may have affected the abnormalities [5].

On the other hand, research focusing on the choice of drug diluents has been limited. We believe that the drug diluents may play an important role because critically ill

\footnotetext{
* Correspondence: yukariaoyagi@yahoo.co.jp

Intensive Care Unit, Department of Anesthesiology, The Jikei University

Hospital, 3-19-18, Nishi-Shinbashi Minato-ku, Tokyo 105-8471, Japan
}

patients generally require many types of drugs, including antibiotics and sedatives $[6,7]$. The total amount of diluents administered may be high enough to introduce abnormalities in serum electrolyte and glucose levels. It is therefore necessary to investigate the impact of diluents on those abnormalities.

The purpose of the present study is to evaluate the effect of drug diluents in critically ill patients. We hypothesized that changing the default diluent from D5W to saline would improve blood glucose control without inducing electrolyte abnormalities.

(c) The Author(s). 2020 Open Access This article is licensed under a Creative Commons Attribution 4.0 International License, which permits use, sharing, adaptation, distribution and reproduction in any medium or format, as long as you give appropriate credit to the original author(s) and the source, provide a link to the Creative Commons licence, and indicate if changes were made. The images or other third party material in this article are included in the article's Creative Commons licence, unless indicated otherwise in a credit line to the material. If material is not included in the article's Creative Commons licence and your intended use is not permitted by statutory regulation or exceeds the permitted use, you will need to obtain permission directly from the copyright holder. To view a copy of this licence, visit http://creativecommons.org/licenses/by/4.0/. The Creative Commons Public Domain Dedication waiver (http://creativecommons.org/publicdomain/zero/1.0/) applies to the data made available in this article, unless otherwise stated in a credit line to the data. 


\section{Materials and methods}

We conducted a before-after, two-group comparative, observational study to retrospectively examine the effect of changing the drug diluent from D5W to saline. The study protocol was approved by The Jikei University Institutional Review Board (31-011[9510]). Because of the retrospective, observational nature of the study, the Board waived the need for written informed consent.

\section{Study setting and participants}

We conducted this study in a mixed medical and surgical intensive care unit (ICU) with 20 beds at The Jikei University Hospital in Tokyo, Japan. During the period July 1, 2015, to December 31, 2018, consecutive patients admitted to the ICU were screened for inclusion. We included adult patients (age $\geq 20$ years) who stayed in the ICU for more than $48 \mathrm{~h}$. We excluded patients with ICU readmission during the same hospitalization period, those with no arterial line, those with end-stage kidney disease as defined by the Kidney Disease: Improving Global Outcomes classification [8], and those with a history of urinary diversion. All study patients were followed up until hospital discharge. We compared blood glucose control and electrolyte abnormalities during the D5W period (July 2015-December 2016) and the saline period (January 2017-December 2018).

\section{Change of our policy}

Before the end of 2016, D5W was automatically selected if the doctor did not specify the diluent when ordering intermittent drugs by the computer ordering system. We observed unstable blood glucose levels in some patients, presumably owing to intermittent D5W infusion. Therefore, on January 1, 2017, we changed the default diluent for intermittent drug sets in our electronic ordering system from D5W to saline. The clinicians were allowed to change the diluent to D5W if deemed clinically necessary.

\section{Variables and outcomes}

We assessed the following variables for 1 week or during the entire ICU stay, whichever was shorter: age, sex, height, weight, body mass index, comorbidities, time from hospitalization to ICU admission, patient category at ICU admission (planned surgical, nonplanned surgical, medical), main damaged organ, Acute Physiology and Chronic Health Evaluation (APACHE) III score [9], serum concentrations during the observation period (sodium, chloride, creatinine, blood glucose), type and volume of administered fluid, length of ICU and hospital stay, and ICU and hospital mortality. Serum concentrations of sodium and chloride were assessed by central laboratory analysis using a LABOSPECT 008 $\alpha$ analyzer (Hitachi High-Technologies Corp, Tokyo, Japan), and blood glucose was assessed by blood gas analysis using an ABL800 FLEX analyzer (Radiometer Medical ApS, Copenhagen, Denmark). Samples were collected at 7:00 AM every morning. Blood gas samples were also collected at the discretion of the attending physician.

The primary outcomes were the incidences of hyperglycemia and hypernatremia during the observation period in consideration of the effect of D5W on blood glucose levels and the effect of saline on serum sodium levels, which may affect the clinical course [6]. The secondary outcomes were the incidences of hyperchloremia, hyponatremia, hypoglycemia, and AKI; blood glucose SD, AKI maximum stage, renal replacement therapy (RRT) requirement, ICU/hospital length of stay; and ICU/hospital mortality.

Hyperglycemia was defined as $\geq 180 \mathrm{mg} / \mathrm{dL}$ [6, 10-12]. Hypoglycemia was defined as $<70 \mathrm{mg} / \mathrm{dL}$ [13]. Hypernatremia was defined as $\geq 145 \mathrm{mmol} / \mathrm{L}[2,5,6,14]$. Hyponatremia was defined as $<135 \mathrm{mmol} / \mathrm{L}[2,5,6]$. Hyperchloremia was defined as $\geq 110 \mathrm{mmol} / \mathrm{L}[5,6,15]$. With respect to sodium, chloride, and blood glucose, the values at the time of ICU admission were defined as the baseline. With respect to creatinine, we defined the baseline value as the mean serum creatinine level measured 7 to 365 days before hospital admission [16]. If baseline creatinine data were not available, we estimated the level according to the equation for the Modification of Diet in Renal Disease for Japanese [17]. Diagnosis of AKI was made according to the Acute Kidney Injury Work Group's Kidney Disease: Improving Global Outcomes definition [8].

\section{Statistical methods}

Blood glucose standard deviation (SD) was calculated from all values measured during the observation period. Data are presented as median (interquartile range) or number (\%), as appropriate. Univariable analyses for categoric variables were conducted using the chi-square or Fisher exact test. For continuous variables, comparisons were performed using the Mann-Whitney $U$ test. For each outcome, patients with an abnormal baseline value were excluded from these analyses. The numbers of excluded patients were reported. To assess the effect of changing the diluent solution, we conducted multivariable analyses for hyperglycemia, hypernatremia, hyperchloremia, blood glucose SD, and AKI diagnosis. Variables in each model were selected according to clinical plausibility and previous studies $[1-7,14,15,18]$. Multivariable logistic regression analysis was used to assess categoric outcomes, and linear regression analysis was used to assess continuous outcomes. Two-sided $p$ values of $<0.05$ were considered statistically significant. Analyses were performed using SPSS version 25.0 (IBM Corp, Armonk, New York, USA), Stata version 16 
(StataCorp, College Station, Texas, USA), and R version 3.6.1 (The R Foundation for Statistical Computing, package Rcmdr/EZR) [19].

\section{Sensitivity analysis}

For the assessment of the fluctuation of results due to different cutoff values for hypernatremia, hyperglycemia, and hyperchloremia, we performed logistic regression analyses with different cutoff values $(\mathrm{Na} 150 \mathrm{mmol} / \mathrm{L} ; \mathrm{Cl}$ $115 \mathrm{mmol} / \mathrm{L}$; Glu $200 \mathrm{mg} / \mathrm{dL}$ ) and linear regression analyses for the each highest value during the observation period.

\section{Results}

A total of 6202 adult patients were admitted to the ICU during the study period. Among those, 844 patients were included in the study: 365 and 479 in the D5W and saline period, respectively (Fig. 1).

Patient characteristics are listed in Table 1 . The median age was 69 years, and $69.2 \%$ were men. The most commonly damaged organ was the cardiovascular system $(40.5 \%)$, followed by the neurologic system (18.1\%). The median levels of serum sodium, chloride, baseline creatinine, and blood glucose at ICU admission were all in the normal range. Patients in the saline group had fewer days from hospitalization to ICU admission and fewer planned surgical admissions than those in the D5W group. Otherwise, there was no significant difference between the two groups regarding patient characteristics.
Details of infusion volume during the observation period are shown in Table 2. Overall, $4845 \mathrm{~mL}$ was administered over a period of 3.99 days. Patients in the saline group received smaller volumes of D5W and larger volumes of saline than those in the D5W group. There was no significant difference between the two groups in the volume of other crystalloids and total volume of those infusions. Intermittent infusion considered as a drug diluent became $21.4 \%$ of the total infusion volume.

Unadjusted primary and secondary outcomes are shown in Table 2. There was no significant difference in the incidence of hyperglycemia between the two groups. The incidence of hypernatremia was significantly greater in the saline group than in the D5W group. Of the secondary outcomes, only the incidence of hyperchloremia was different, being greater in the saline group than in the D5W group.

Box plots for daily serum blood glucose, sodium, and chloride levels are shown in Figs. 2, 3 and 4, respectively. Patients in the saline group had greater sodium levels on days 1 to 5 and greater chloride levels on days 2 to 7 .

Results of multivariable regression analyses for primary outcomes are shown in Table 3 (for secondary outcomes are shown in Table 4). In the adjusted models, the diluent group was independently associated with hypernatremia (adjusted odds ratio (OR), 2.43; 95\% confidence interval (CI), 1.54-3.82) and hyperchloremia (adjusted OR, 2.09; 95\% CI, 1.31-3.34). There was no significant association between the diluent group and hyperglycemia (adjusted OR, 1.08; 95\% CI, 0.77-1.5), blood glucose SD (beta coefficient, $0.4 ; 95 \% \mathrm{CI},-1.37$ to

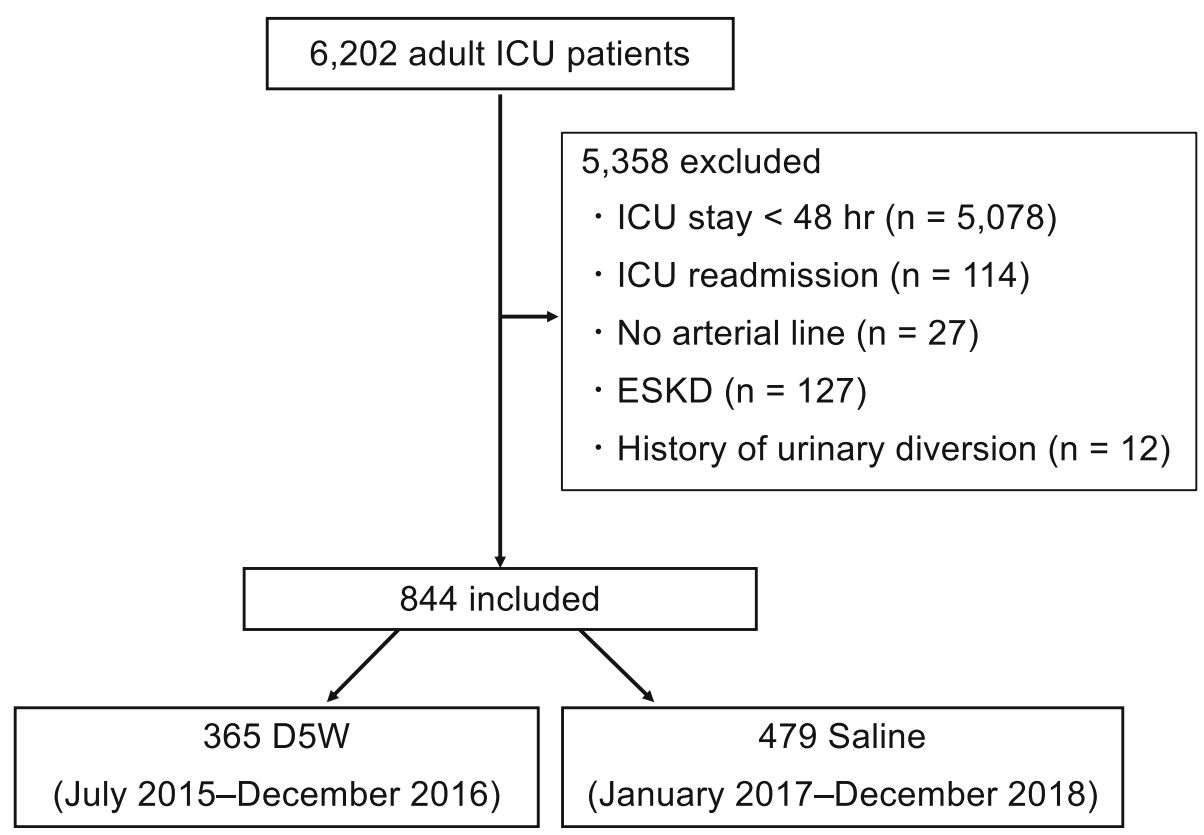

Fig. 1 Patient flow. D5W, dextrose 5\% in water; ESKD, end-stage kidney disease; ICU, intensive care unit 
Table 1 Patient characteristics

\begin{tabular}{|c|c|c|c|c|}
\hline & Total $(N=844)$ & D5W $(n=365)$ & Saline $(n=479)$ & $p$ value \\
\hline Age, years & $69(55-77)$ & $68(56-75)$ & $69(55-78)$ & 0.313 \\
\hline Male sex & $584(69.2)$ & $244(66.8)$ & $340(71.0)$ & 0.202 \\
\hline Height, cm & $164(157-170)$ & $164(158-170)$ & $164(157-170)$ & 0.593 \\
\hline Weight, kg & $60(50-70)$ & $61(51-70)$ & $60(50-70)$ & 0.62 \\
\hline Body mass index & $22(20-25)$ & $23(20-25)$ & $22(20-25)$ & 0.295 \\
\hline \multicolumn{5}{|l|}{ Comorbidity } \\
\hline Heart failure & $8(0.9)$ & $2(0.5)$ & $6(1.3)$ & 0.477 \\
\hline Respiratory failure & $17(2.0)$ & $5(1.4)$ & $12(2.5)$ & 0.325 \\
\hline Liver cirrhosis & $30(3.6)$ & $16(4.4)$ & $14(2.9)$ & 0.266 \\
\hline Hematologic malignancy & $45(5.3)$ & $20(5.5)$ & $25(5.2)$ & 0.878 \\
\hline Metastatic malignancy & $34(4.0)$ & $12(3.3)$ & $22(4.6)$ & 0.381 \\
\hline Immunosuppression & $95(11.3)$ & 39 (10.7) & $56(11.7)$ & 0.662 \\
\hline Time from hospitalization to ICU, days & $2(0-7)$ & $3(0-8)$ & $1(0-6)$ & 0.005 \\
\hline Patient category & & & & 0.005 \\
\hline Planned surgical & $291(34.5)$ & $150(41.1)$ & $141(29.4)$ & \\
\hline Nonplanned surgical & $212(25.1)$ & $83(22.7)$ & $129(26.9)$ & \\
\hline Medical from ward & $185(21.9)$ & $75(20.5)$ & $110(23.0)$ & \\
\hline Medical from ED & $156(18.5)$ & 57 (15.6) & 99 (20.7) & \\
\hline Main damaged organ & & & & 0.745 \\
\hline Cardiovascular & $342(40.5)$ & $156(42.7)$ & $186(38.8)$ & \\
\hline Neurologic & $153(18.1)$ & $65(17.8)$ & $88(18.4)$ & \\
\hline Respiratory & $127(15.0)$ & 49 (13.4) & $78(16.3)$ & \\
\hline Digestive & $120(14.2)$ & $51(14.0)$ & $69(14.4)$ & \\
\hline Other & $102(12.1)$ & $44(12.1)$ & $58(12.1)$ & \\
\hline APACHE III score & $71(56-88)$ & $71(57-86)$ & $72(54-88)$ & 0.916 \\
\hline \multicolumn{5}{|l|}{ Data at ICU admission } \\
\hline Sodium, mmol/L & $140(137-142)$ & $140(137-142)$ & $140(137-143)$ & 0.274 \\
\hline Chloride, $\mathrm{mmol} / \mathrm{L}$ & $107(103-111)$ & $108(104-111)$ & $107(103-111)$ & 0.105 \\
\hline Blood glucose, mg/dL & $137(115-169)$ & $136(113-169)$ & $138(115-169)$ & 0.525 \\
\hline Baseline creatinine, mg/dL & $0.85(0.74-0.99)$ & $0.84(0.72-0.98)$ & $0.85(0.75-1.00)$ & 0.448 \\
\hline
\end{tabular}

Data are presented as median (interquartile range) or number (\%)

APACHE III Acute Physiology and Chronic Health Evaluation III, D5W dextrose 5\% in water, ED emergency department, ICU intensive care unit

2.18), or AKI (adjusted OR, 1.11; 95\% CI, 0.79-1.56) in the adjusted model. The results of sensitivity analyses are shown in supplemental Table 1 and 2. Results of the analyses were similar to those in the main ones.

\section{Discussion}

\section{Key findings}

We conducted a before-after, two-group comparative study that examined the effect of changing the drug diluent from D5W to saline. Patients in the saline group received smaller volumes of D5W and larger volumes of saline compared with the D5W diluent group. Contrary to our initial expectation, there was no significant difference in the incidence of hyperglycemia or blood glucose
SD. However, the incidence of hypernatremia was significantly greater in the saline group than in the D5W group. There was no significant difference in incidence of AKI or mortality between the two groups.

\section{Comparison with previous studies}

There are few previous studies that evaluated the effect of diluent on patient outcomes [6,7]. One before-after study, in which the drug diluent was changed from saline to D5W, reported that the incidence of hyperchloremia decreased (adjusted OR, 0.50; 95\% CI, 0.27-0.94), without difficulty in blood glucose control [6]. That study reported that diluents accounted for a large part of the total infusion volume (63\%). In contrast, the diluent 
Table 2 Infusion volume, electrolyte and glucose abnormalities, acute kidney injury, and other outcomes

\begin{tabular}{|c|c|c|c|c|}
\hline & Total $(N=844)$ & D5W $(n=365)$ & Saline $(n=479)$ & $p$ value \\
\hline Observation period, days & $3.99(2.87-6.80)$ & $3.89(2.88-6.44)$ & $4.13(2.86-7.00)$ & 0.233 \\
\hline \multicolumn{5}{|l|}{ Continuous infusion } \\
\hline Saline, mL & $4(0-145)$ & $0(0-126)$ & $27(0-164)$ & 0.009 \\
\hline $\mathrm{D} 5 \mathrm{~W}, \mathrm{~mL}$ & $254(50-608)$ & $257(68-557)$ & $253(42-634)$ & 0.851 \\
\hline Other crystalloids, mL & $2492(1506-3586)$ & $2525(1658-3620)$ & $2430(1359-3568)$ & 0.427 \\
\hline \multicolumn{5}{|l|}{ Intermittent infusion } \\
\hline Saline, mL & $650(150-1326)$ & $150(0-450)$ & $1000(650-1750)$ & $<0.001$ \\
\hline D5W, mL & $387(0-916)$ & $800(535-1365)$ & $0(0-250)$ & $<0.001$ \\
\hline Other crystalloids, mL & $0(0-500)$ & $0(0-500)$ & $0(0-500)$ & 0.336 \\
\hline Total infusion, mL & $4845(3443-6,762)$ & $4697(3475-6502)$ & $4883(3381-6988)$ & 0.541 \\
\hline Saline, mL & 795 (250-1759) & $207(50-700)$ & $1150(700-2050)$ & $<0.001$ \\
\hline $\mathrm{D} 5 \mathrm{~W}, \mathrm{~mL}$ & 770 (312-1493) & $1220(752-1896)$ & $418(170-1003)$ & $<0.001$ \\
\hline Other crystalloids, mL & $2802(1702-3988)$ & $2850(1894-3896)$ & $2759(1513-4036)$ & 0.423 \\
\hline Hyperglycemia $^{a}$ & $374 / 655(57.1)$ & $161 / 285(56.5)$ & 213/370 (57.6) & 0.811 \\
\hline Hypernatremia ${ }^{b}$ & 160/735 (21.8) & 47/321 (14.6) & $113 / 414(27.3)$ & $<0.001$ \\
\hline Blood glucose $\mathrm{SD}, \mathrm{mg} / \mathrm{dL}^{\mathrm{c}}$ & $22(17-30)$ & $21(16-29)$ & $23(17-30)$ & 0.235 \\
\hline Hypoglycemia $^{d}$ & 88/833 (10.6) & 29/359 (8.1) & $59 / 474(12.0)$ & 0.053 \\
\hline Hyponatremia $^{e}$ & 95/723 (13.1) & 44/313 (14.1) & $51 / 410(12.4)$ & 0.579 \\
\hline Hyperchloremia ${ }^{f}$ & 160/533 (30.0) & 45/221 (20.4) & 115/312 (36.9) & $<0.001$ \\
\hline AKI diagnosis ${ }^{9}$ & $377 / 639$ (59.0) & 165/283 (58.3) & 212/356 (59.5) & 0.808 \\
\hline AKI maximum stage ${ }^{g}$ & & & & 0.826 \\
\hline Stage 1 & $204(54.1)$ & $85(51.5)$ & $119(56.1)$ & \\
\hline Stage 2 & $132(35.0)$ & $61(37.0)$ & $71(33.5)$ & \\
\hline Stage 3 & $41(10.9)$ & 19 (11.6) & $22(10.4)$ & \\
\hline RRT requirement ${ }^{g}$ & $20(3.1)$ & $6(2.1)$ & $14(3.9)$ & 0.254 \\
\hline ICU LOS, days & $4.0(2.9-6.8)$ & $3.9(2.9-6.4)$ & $4.1(2.9-7.3)$ & 0.269 \\
\hline Hospital LOS, days & $38(23-62)$ & $40(24-62)$ & $37(23-62)$ & 0.497 \\
\hline ICU mortality & $50(5.9)$ & $24(6.6)$ & $26(5.4)$ & 0.557 \\
\hline Hospital mortality & $125(14.8)$ & $56(15.3)$ & $69(14.4)$ & 0.769 \\
\hline
\end{tabular}

Data are presented as median (interquartile range) or number (\%)

$A K I$ acute kidney injury, D5W dextrose $5 \%$ in water, ICU intensive care unit, LOS length of stay, RRT renal replacement therapy, SD standard deviation

${ }^{a}$ Patients with baseline blood glucose $\geq 180 \mathrm{mg} / \mathrm{dL}$ were excluded (189 patients)

${ }^{b}$ Patients with baseline sodium $\geq 145 \mathrm{mmol} / \mathrm{L}$ were excluded (109 patients)

'Patients with blood glucose $<70 \mathrm{mg} / \mathrm{dL}$ or $\geq 180 \mathrm{mg} / \mathrm{dL}$ were excluded (200 patients)

${ }^{d}$ Patients with baseline blood glucose $<70 \mathrm{mg} / \mathrm{dL}$ were excluded (11 patients)

${ }^{e}$ Patients with baseline sodium $<135 \mathrm{mmol} / \mathrm{L}$ were excluded (121 patients)

${ }^{f}$ Patients with baseline chloride $\geq 110 \mathrm{mmol} / \mathrm{L}$ were excluded ( 311 patients)

${ }^{g}$ Patients who received a diagnosis of AKI at ICU admission were excluded (205 patients)

amounted to just over $20 \%$ of all of the administered formulations in our present study. However, even with such a small percentage, changing diluent from D5W to saline increased the incidences of hypernatremia and hyperchloremia. These results highlight the magnitude of the effect of diluent choice on electrolyte abnormalities, consistent with the previous studies $[6,7]$.

Regarding the incidence of hyperglycemia, the difference between the D5W group and saline group was not reported in the previous study $(82.3 \%$ vs. $88.1 \%)$ [6]. Our present study found that changing default diluents from D5W to saline did not improve the incidence of hyperglycemia, which is consistent with the previous study [6]. We also found no significant difference in blood glucose SD between the two groups, implying glucose stability. This might be because the amount of glucose in D5W ( $2.5 \mathrm{~g}$ in $50 \mathrm{~mL}$ or $5 \mathrm{~g}$ in $100 \mathrm{~mL}$ ) is too small to affect blood glucose values. In addition, blood glucose has an adjustment medicine, insulin, as an antagonist, unlike electrolytes. 


\section{-D5W $\square$ Saline}

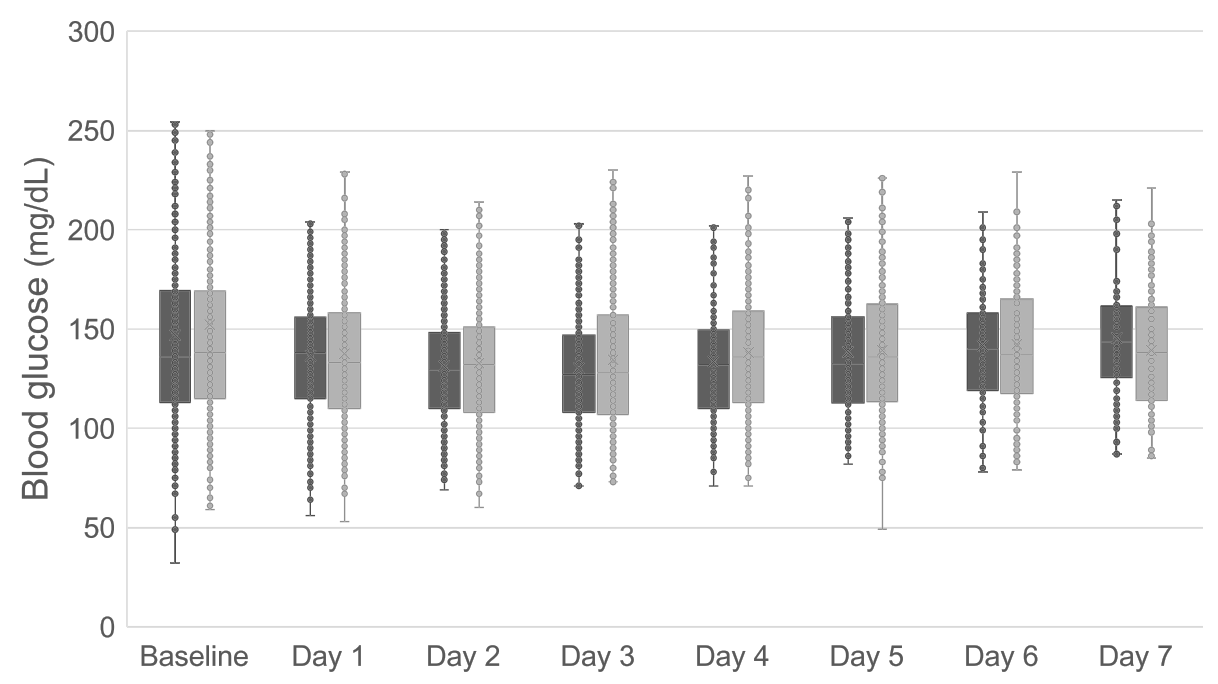

Fig. 2 Box plots for daily blood glucose levels. The box plots show median and interquartile range. D5W, dextrose 5\% in water

Hypernatremia is thought to be due to unreplaced water loss, water loss into cells, or excess sodium. Among those mechanics, hypernatremia induced by infusion may be based on sodium overload, which is regarded as iatrogenic hypernatremia. Hypernatremia has been reported to be associated with increased mortality. In a secondary analysis of the European Surgical Outcome Study, which provided data describing 46,539 patients undergoing inpatient noncardiac surgery, moderate to severe hypernatremia was independently associated with mortality (adjusted OR, 3.4; 95\% CI, 2.0-6.0) [3]. Similarly, a relation between hyperchloremia and $\mathrm{AKI} / \mathrm{mor}-$ tality has been suggested [20, 21]. A systematic review and meta-analysis to assess the relation between the chloride content of intravenous resuscitation fluids and patient outcomes for the perioperative or intensive care setting showed that high-chloride fluids were associated with the incidence of AKI [20]. However, in the present study, there was no significant difference in AKI incidence or mortality between the two groups, possibly owing to lack of adequate sample size to evaluate these outcomes.

\section{Significance and implications}

We focused on the effect of the choice of drug diluent on outcomes in critically ill patients. We changed the

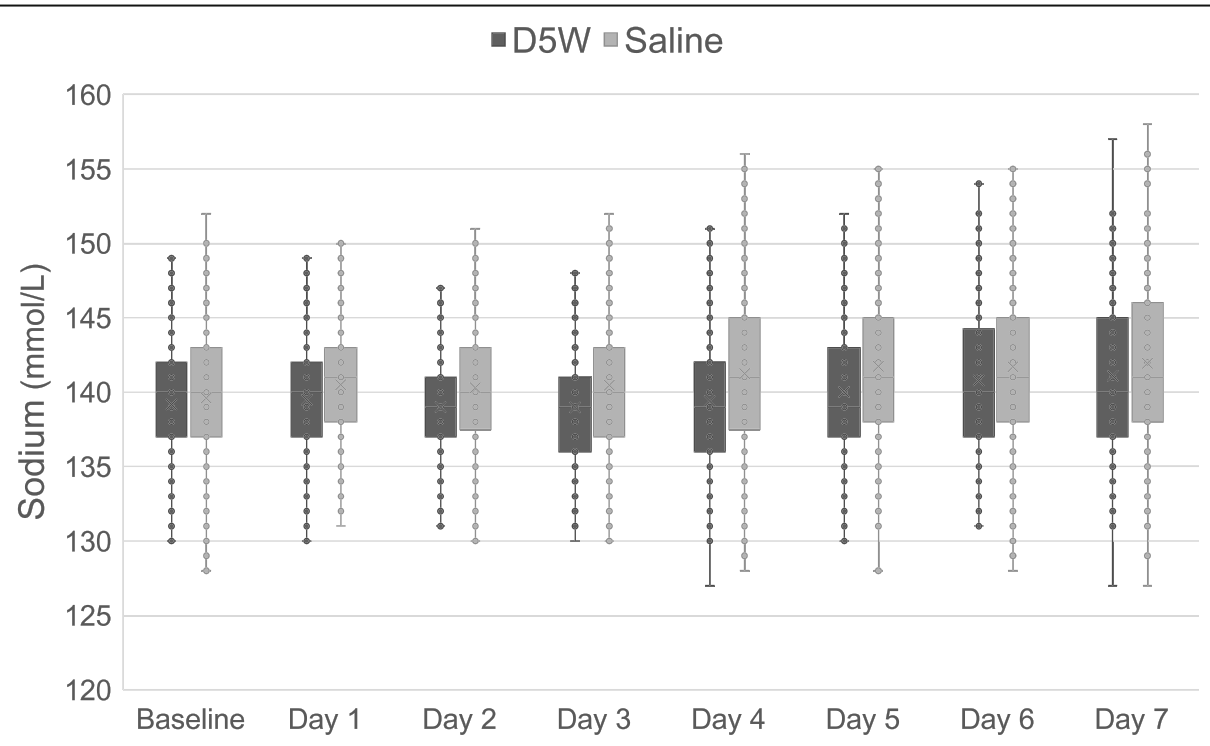

Fig. 3 Box plots for daily serum sodium levels. The box plots show median and interquartile range. D5W, dextrose 5\% in water 


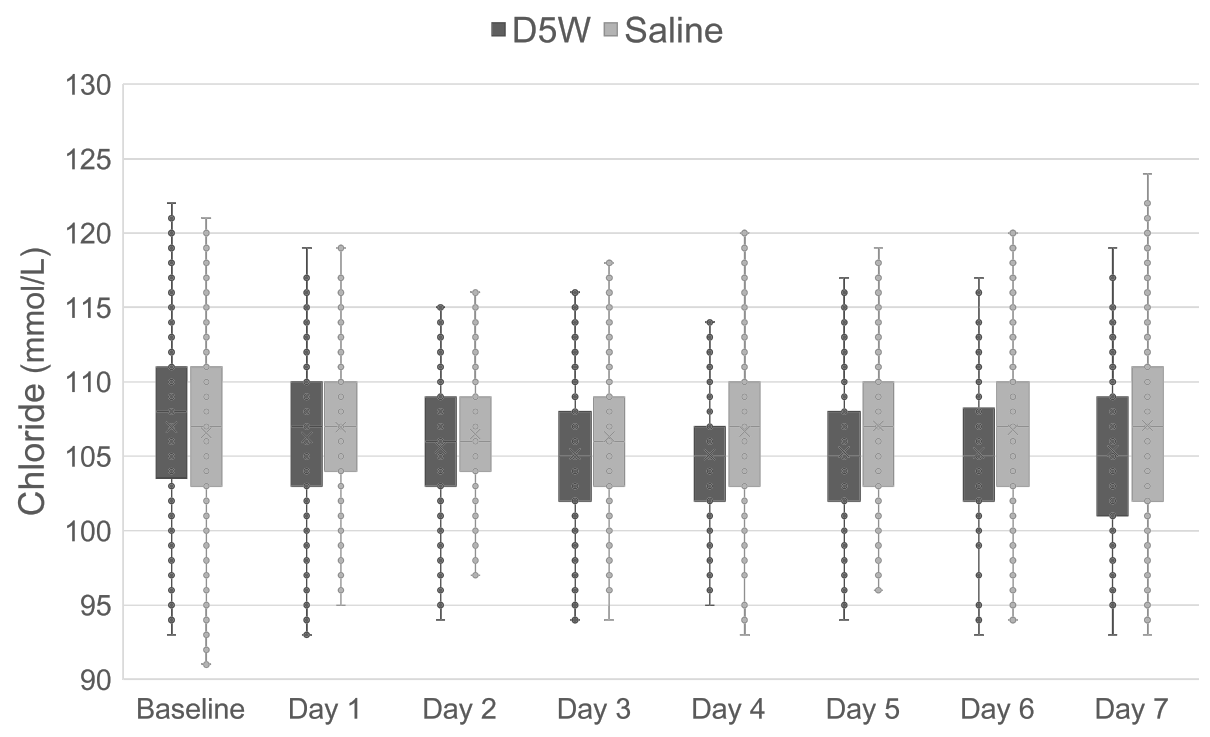

Fig. 4 Box plots for daily serum chloride levels. The box plots show median and interquartile range. D5W, dextrose 5\% in water

Table 3 Multivariable regression analyses for primary outcomes

\begin{tabular}{|c|c|c|}
\hline Outcome & Adjusted OR/ $\beta$-coefficient $(95 \% \mathrm{Cl})$ & $p$ value \\
\hline \multicolumn{3}{|l|}{ Hyperglycemia $^{a}$} \\
\hline Diluent group (saline) & $1.08(0.77-1.5)$ & 0.671 \\
\hline Blood glucose at ICU admission, $\mathrm{mg} / \mathrm{dL}$ & $1.01(1.01-1.02)$ & $<0.001$ \\
\hline Age, year & $1.01(1.0-1.02)$ & 0.097 \\
\hline Weight, kg & $1.0(0.99-1.01)$ & 0.926 \\
\hline APACHE III score & $1.02(1.01-1.03)$ & $<0.001$ \\
\hline Time from hospitalization to ICU, days & $1.01(0.99-1.02)$ & 0.339 \\
\hline \multicolumn{3}{|l|}{ Patient category } \\
\hline Planned surgical & Reference & \\
\hline Nonplanned surgical & $0.73(0.48-1.13)$ & 0.158 \\
\hline Medical from ward & $1.11(0.65-1.91)$ & 0.700 \\
\hline Medical from ED & $0.87(0.54-1.42)$ & 0.582 \\
\hline \multicolumn{3}{|l|}{ Hypernatremia $^{b}$} \\
\hline Diluent group (Saline) & $2.43(1.54-3.82)$ & $<0.001$ \\
\hline Sodium at ICU admission, mmol/L & $1.18(1.11-1.26)$ & $<0.001$ \\
\hline Age, year & $1.01(0.99-1.02)$ & 0.373 \\
\hline Weight, kg & $1.0(0.98-1.02)$ & 0.997 \\
\hline APACHE III score & $1.02(1.01-1.03)$ & $<0.001$ \\
\hline Time from hospitalization to ICU, days & $1.01(1.0-1.02)$ & 0.070 \\
\hline \multicolumn{3}{|l|}{ Patient category } \\
\hline Planned surgical & Reference & \\
\hline Nonplanned surgical & $1.74(0.97-3.12)$ & 0.061 \\
\hline Medical from ward & $2.53(1.33-4.82)$ & 0.005 \\
\hline Medical from ED & $1.70(0.89-3.27)$ & 0.109 \\
\hline
\end{tabular}

APACHE III Acute Physiology and Chronic Health Evaluation III, ED emergency department, ICU intensive care unit, OR odds ratio ${ }^{a}$ Patients with baseline blood glucose $\geq 180 \mathrm{mg} / \mathrm{dL}$ were excluded (189 patients)

${ }^{b}$ Patients with baseline sodium $\geq 145 \mathrm{mmol} / \mathrm{L}$ were excluded (109 patients) 
Table 4 Multivariable regression analyses for secondary outcomes

\begin{tabular}{|c|c|c|}
\hline Outcome & Adjusted OR/ $\beta$-coefficient $(95 \% \mathrm{Cl})$ & $p$ value \\
\hline \multicolumn{3}{|l|}{ Hyperchloremia $^{a}$} \\
\hline Diluent group (Saline) & $2.09(1.31-3.34)$ & 0.002 \\
\hline Chloride at ICU admission, mmol/L & $1.15(1.08-1.22)$ & $<0.001$ \\
\hline Age, year & $1.0(0.98-1.02)$ & 0.976 \\
\hline Weight, kg & $1.0(0.99-1.02)$ & 0.632 \\
\hline APACHE III score & $1.02(1.01-1.03)$ & $<0.001$ \\
\hline Time from hospitalization to ICU, days & $1.0(0.99-1.01)$ & 0.88 \\
\hline \multicolumn{3}{|l|}{ Patient category } \\
\hline Planned surgical & Reference & \\
\hline Unplanned surgical & $2.37(1.16-4.83)$ & 0.018 \\
\hline Medical from ward & $2.23(1.02-4.88)$ & 0.044 \\
\hline Medical from ED & $1.88(0.86-4.09)$ & 0.112 \\
\hline \multicolumn{3}{|l|}{ Blood glucose SD ${ }^{b}$} \\
\hline Diluent group (Saline) & $0.4(-1.37$ to 2.18$)$ & 0.655 \\
\hline Blood glucose at ICU admission, mg/dL & $0.03(0-0.07)$ & 0.089 \\
\hline Age, year & $0.08(0.02-0.15)$ & 0.01 \\
\hline Weight, kg & $-0.07(-0.14$ to -0.01$)$ & 0.029 \\
\hline APACHE III score & $0.06(0.02-0.98)$ & 0.006 \\
\hline Time from hospitalization to ICU, days & $0.02(-0.04$ to 0.09$)$ & 0.490 \\
\hline \multicolumn{3}{|l|}{ Patient category } \\
\hline Planned surgical & Reference & \\
\hline Unplanned surgical & 0.31 ( -1.96 to 2.58$)$ & 0.788 \\
\hline Medical from ward & $5.72(2.91-8.52)$ & $<0.001$ \\
\hline Medical from ED & $0.87(-1.71$ to 3.44$)$ & 0.51 \\
\hline \multicolumn{3}{|l|}{ AKI diagnosis ${ }^{c}$} \\
\hline Diluent group (Saline) & $1.11(0.79-1.56)$ & 0.542 \\
\hline Creatinine at ICU admission, mg/dL & $2.57(1.31-5.05)$ & 0.006 \\
\hline Chloride at ICU admission, mmol/L & $1.0(0.96-1.03)$ & 0.816 \\
\hline Age, year & $0.99(0.98-1.01)$ & 0.347 \\
\hline Weight, kg & $1.01(0.99-1.02)$ & 0.273 \\
\hline APACHE III score & $1.02(1.01-1.03)$ & $<0.001$ \\
\hline Time from hospitalization to ICU, days & $0.99(0.98-1.0)$ & 0.034 \\
\hline \multicolumn{3}{|l|}{ Patient category } \\
\hline Planned surgical & Reference & \\
\hline Unplanned surgical & $0.43(0.27-0.68)$ & $<0.001$ \\
\hline Medical from ward & $0.94(0.51-1.75)$ & 0.854 \\
\hline Medical from ED & $1.31(0.72-2.38)$ & 0.372 \\
\hline
\end{tabular}

${ }^{a}$ Patients with baseline chloride $\geq 110 \mathrm{mmol} / \mathrm{L}$ were excluded (311 patients)

${ }^{b}$ Patients with blood glucose $<70 \mathrm{mg} / \mathrm{dL}$ or $\geq 180 \mathrm{mg} / \mathrm{dL}$ were excluded (200 patients)

cPatients who received a diagnosis of AKI at ICU admission were excluded (205 patients)

AKI acute kidney injury, APACHE III Acute Physiology and Chronic Health Evaluation III, ED emergency department, ICU intensive care unit, OR odds ratio, SD standard deviation

diluent from D5W to saline for the purpose of improving blood glucose control based on our experience with several patients. However, we found no effect on glucose control and did find significant effects on the incidences of hypernatremia and hyperchloremia. Considering the results of the present study in conjunction with previous studies, D5W appears to be a better choice as default diluent for 
critically ill patients, although it is necessary to select diluents according to the condition of individual patients. Since only observational studies, including the present study, have been conducted on this issue, randomized interventional studies are needed to confirm the findings.

\section{Strengths and limitations}

We believe that the present study has the largest sample size among the studies assessing the choice of drug diluents for critically ill patients [6, 7]. Furthermore, we used the Kidney Disease: Improving Global Outcomes classification [8] to diagnose AKI, which includes more detailed diagnostic criteria compared with those used in the previous studies. However, our study has several limitations. First, there were confounders that could not be included due to the retrospective observational nature of our study, e.g., past history of diabetes and physiological status. Second, because this was a single-center study and the results might have been influenced by the local clinical practice, our findings may limit the generalizability. Third, we excluded patients without arterial line, those with end-stage kidney disease, and those with abnormal baseline values of serum electrolytes and glucose, possibly leading to selection bias. Fourth, owing to the before-after study design, there was a difference in the duration of observation between the two groups (D5W 18 months; saline 24 months). This is because we changed the protocol for blood glucose control in July 2015. In addition, there were some differences in the patient background (days from hospitalization to ICU admission and scheduled surgery). However, our findings in the multivariate analyses including those factors found similar results to those in the univariate analyses. Fifth, some drugs require to be dissolved in saline or D5W only, which cannot be changed by physicians. We could not evaluate the impact of these drugs. Finally, we did not collect information for adverse events related to electrolyte abnormalities other than AKI and mortality. Therefore, we could not show the comprehensive impact for the choice of drug diluents. Further prospective studies are warranted.

\section{Conclusions}

Changing the drug diluent default from D5W to saline had no effect on blood glucose control but increased the incidence of hypernatremia and hyperchloremia, without affecting the incidence of AKI or mortality. D5W may be a better choice as a default diluent for critically ill patients. Randomized interventional studies are warranted to confirm the findings.

\section{Supplementary information}

Supplementary information accompanies this paper at https://doi.org/10. 1186/s40560-020-00489-6.

Additional file 1: Supplemental Table 1. Sensitivity analyses for multivariable logistic regression. Supplemental Table 2. Sensitivity analyses for multivariable linear regression.

\section{Abbreviations}

D5W: 5\% dextrose in water; AKI: Acute kidney injury; ICU: Intensive care unit; APACHE III: Acute Physiology and Chronic Health Evaluation III; SD: Standard deviation; RRT: Renal replacement therapy; OR: Odds ratio; Cl: Confidence interval

\section{Acknowledgements}

Not applicable.

\section{Authors' contributions}

YA has full access to all study data and takes responsibility for its integrity. Study concept and design: YA, TY, and SU. Data acquisition: YA and SU. Data analysis and interpretation: YA, TY, and SU. Manuscript drafting: YA. Critical revision of the manuscript for important intellectual content: YA, TY, SU, MT, and SU. All authors read and approved the final manuscript.

\section{Funding}

This research did not receive any specific grant from funding agencies in the public, commercial, or not-for-profit sectors.

\section{Availability of data and materials}

The datasets used and/or analyzed during the current study are available from the corresponding author on reasonable request.

For more information please email our Research Data Team.

\section{Ethics approval and consent to participate}

The study protocol was approved by The Jikei University Institutional Review Board (31-011[9510]) and the ethics committees of all other participating hospitals with an opt-out policy from the patient or their proxy.

\section{Consent for publication}

Not applicable.

\section{Competing interests}

The authors declare that they have no competing interests.

Received: 9 July 2020 Accepted: 3 September 2020

Published online: 11 September 2020

\section{References}

1. Egi M, Bellomo R, Stachowski E, et al. Variability of blood glucose concentration and short-term mortality in critically ill patients. Anesthesiology. 2006;105:244-52.

2. Cecconi M, Hochrieser H, Chew M, European Surgical Outcomes Study (EuSOS) group for the Trials groups of the European Society of Intensive Care Medicine and the European Society of Anaesthesiology, et al. Preoperative abnormalities in serum sodium concentrations are associated with higher in-hospital mortality in patients undergoing major surgery. $\mathrm{Br} J$ Anaesth. 2016;116:63-9.

3. Boniatti MM, Cardoso PR, Castilho RK, et al. Is hyperchloremia associated with mortality in critically ill patients? A prospective cohort study. I Crit Care. 2011;26:175-9.

4. Yunos NM, Bellomo R, Hegarty C, et al. Association between a chlorideliberal vs chloride-restrictive intravenous fluid administration strategy and kidney injury in critically ill adults. JAMA. 2012;308:1566-72.

5. Semler MW, Self WH, Wanderer JP, et al. SMART Investigators and the Pragmatic Critical Care Research Group: Balanced crystalloids versus saline in critically ill adults. N Engl J Med. 2018;378:829-39.

6. Magee CA, Bastin MLT, Laine ME, et al. Insidious harm of medication diluents as a contributor to cumulative volume and hyperchloremia: a prospective, open-label, sequential period pilot study. Crit Care Med. 2018; 46:1217-23. 
7. Choo WP, Groeneveld AB, Driessen RH, et al. Normal saline to dilute parenteral drugs and to keep catheters open is a major and preventable source of hypernatremia acquired in the intensive care unit. J Crit Care. 2014:29:390-4.

8. Kidney Disease: Improving Global Outcomes (KDIGO) Acute Kidney Injury Work Group. KDIGO clinical practice guideline for acute kidney injury. Kidney Int Suppl. 2012;2:1-138.

9. Knaus WA, Wagner DP, Draper EA, et al. The APACHE III prognostic system. Risk prediction of hospital mortality for critically ill hospitalized adults. Chest. 1991;100:1619-36.

10. American Diabetes Association. Standards of Medical Care in Diabetes-2019 abridged for primary care providers. Clin Diabetes. 2019;37:11-34.

11. Jacobi J, Bircher N, Krinsley J, et al. Guidelines for the use of an insulin infusion for the management of hyperglycemia in critically ill patients. Crit Care Med. 2012:40:3251-76.

12. Oksanen T, Skrifvars MB, Varpula T, et al. Strict versus moderate glucose control after resuscitation from ventricular fibrillation. Intensive Care Med. 2007:33:2093-100

13. Finfer $\mathrm{S}$, Liu B, Chittock DR, et al. NICE-SUGAR Study Investigators: Hypoglycemia and risk of death in critically ill patients. N Engl J Med. 2012; 367:1108-18.

14. Ni HB, Hu XX, Huang XF, et al. Risk factors and outcomes in patients with hypernatremia and sepsis. Am J Med Sci. 2016;351:601-5.

15. Neyra JA, Canepa-Escaro F, Li X, et al. Acute Kidney Injury in Critical Illness Study Group: Association of hyperchloremia with hospital mortality in critically ill septic patients. Crit Care Med. 2015:43:1938-44.

16. Siew ED, Ikizler TA, Matheny ME, et al. Estimating baseline kidney function in hospitalized patients with impaired kidney function. Clin J Am Soc Nephrol. 2012;7:712-9.

17. Matsuo S, Imai E, Horio M, Collaborators developing the Japanese equation for estimated GFR, et al. Revised equations for estimated GFR from serum creatinine in Japan. Am J Kidney Dis. 2009;53:982-92.

18. Waite MD, Fuhrman SA, Badawi $\mathrm{O}$, et al. Intensive care unit-acquired hypernatremia is an independent predictor of increased mortality and length of stay. J Crit Care. 2013;28:405-12.

19. Kanda Y. Investigation of the freely-available easy-to-use software "EZR" (Easy R) for medical statistics. Bone Marrow Transplant. 2013;48:452-8. https://doi.org/10.1038/bmt.2012.244 Advance online publication 3 December 2012.

20. Krajewski ML, Raghunathan K, Paluszkiewicz SM, et al. Meta-analysis of highversus low-chloride content in perioperative and critical care fluid resuscitation. Br J Surg. 2015;102:24-36.

21. McCluskey SA, Karkouti K, Wijeysundera D, et al. Hyperchloremia after noncardiac surgery is independently associated with increased morbidity and mortality: a propensity-matched cohort study. Anesth Analg. 2013;117 $412-21$.

\section{Publisher's Note}

Springer Nature remains neutral with regard to jurisdictional claims in published maps and institutional affiliations.

\section{Ready to submit your research? Choose BMC and benefit from:}

- fast, convenient online submission

- thorough peer review by experienced researchers in your field

- rapid publication on acceptance

- support for research data, including large and complex data types

- gold Open Access which fosters wider collaboration and increased citations

- maximum visibility for your research: over $100 \mathrm{M}$ website views per year

At BMC, research is always in progress.

Learn more biomedcentral.com/submissions 